OPEN ACCESS

Edited by:

Lawrence Jun Zhang,

University of Auckland,

New Zealand

Reviewed by:

Shabnam Hamdi,

Pars Capital International Inc.,

Canada

Rocio Guil,

University of Cádiz, Spain

*Correspondence:

Samsilah Roslan

samsilah@upm.edu.my

Specialty section:

This article was submitted to Educational Psychology,

a section of the journal

Frontiers in Psychology

Received: 03 March 2021

Accepted: 15 April 2021

Published: 14 June 2021

Citation:

Sabouripour F, Roslan S, Ghiami Z and Memon MA (2021) Mediating Role of Self-Efficacy in the

Relationship Between Optimism,

Psychological Well-Being, and Resilience Among Iranian Students.

Front. Psychol. 12:675645.

doi: 10.3389/fpsyg.2021.675645

\section{Mediating Role of Self-Efficacy in the Relationship Between Optimism, Psychological Well-Being, and Resilience Among Iranian Students}

\author{
Fatemeh Sabouripour ${ }^{1}$, Samsilah Roslan ${ }^{2 *}$, Zeinab Ghiami ${ }^{3}$ and Mumtaz Ali Memon ${ }^{4}$ \\ ${ }^{1}$ Faculty of Health Sciences, University of Applied Sciences, Giessen, Germany, ${ }^{2}$ Faculty of Educational Studies, Universiti \\ Putra Malaysia, Serdang, Malaysia, ${ }^{3}$ Faculty of Psychology and Sports Science, University of Münster, Münster, Germany, \\ ${ }^{4}$ NUST Business School, National University of Sciences and Technology (NUST), Islamabad, Pakistan
}

The present study aims to examine whether self-efficacy mediates the relationship between optimism, dimensions of psychological well-being, and resilience among Iranian students. The participants in this study included 251 Iranian students from Universiti Putra Malaysia (UPM). Structural equation modeling using AMOS 20.0 was used to analyze the data. The results indicated that there were significant relationships between optimism, dimensions of psychological well-being, and resilience among Iranian students of UPM. The study findings presented that self-efficacy mediated the relationship between dimensions of psychological well-being (environmental mastery, autonomy, selfacceptance, positive relations with others, personal growth, and purpose in life) and resilience among Iranian students of UPM. Furthermore, self-efficacy was not observed to mediate the influence of optimism on resilience among Iranian students of UPM. The study's findings help to understand the interrelationship between self-efficacy, various dimensions of psychological well-being, and resilience. Consequently, counselors, psychologists, and instructors can develop and plan valuable strategies to enhance students' psychological factors.

Keywords: optimism, psychological well-being, self-efficacy, resilience, international students

\section{INTRODUCTION}

International students face changes in every aspect of life, including geographical location, weather conditions, food, language, cultural habits, and behaviors (Mori, 2000; Titrek et al., 2016). Psychological problems (anxiety, stress, depression) among international students increase because of these changes (Takeuchi et al., 2007; Mesidor and sly, 2016). According to a study conducted by Talebloo and Baki (2013) among Universiti Putra Malaysia students from Iran, Yemen, and Saudi Arabia, faced various challenges during their studies. Furthermore, the Iranian Students' Association in UPM (ISAM) has stated that Iranian students at Universiti Putra Malaysia face numerous problems and challenges. The main concerns of the students 
stem from financial issues, communication problems, and academic difficulties. In this regard, international students need to experience a period of adjustment to various educational and social situations. Therefore, students must understand the importance of adjustment and its related factors (Misra et al., 2003). In this respect, Mesidor and Sly (2016) indicated that the level of self-efficacy among international students was significantly related to students' psychological adjustment.

Moreover, self-efficacy may play a role in how students feel about themselves, and whether they effectively accomplish their goals in life (Bartimote-Aufflick et al., 2016). Confidence in taking control over an individual's behavior, social environment, and motivation can reflect self-efficacy (Bandura, 1977). Self-efficacy is a universal psychological need that controls an individual's cognition, emotions, and decisions related to psychological well-being (Komarraju and Nadler, 2013). Consequently, self-efficacy is critical in stress management, influencing the stressor assessment, and the option and implementation of methods to deal with them (Villada et al., 2017). As a result, people who have high self-efficacy see potentially challenging situations as opportunities rather than risks (Liu and $\mathrm{Li}, 2018$ ). Compared to people who have poor self-efficacy, they are more likely to use highly adaptive coping mechanisms (Chang and Edwards, 2015; Zhao et al., 2015). Hence, self-efficacy is an essential personal resource for university students to prevent stressors and promote adaptive adjustment to this formative stage (Morton et al., 2014; Denovan and Macaskill, 2017).

As Lightsey (2006) and Speight (2009) have reported, students' self-efficacy is a significant predictor of their resilience. Moreover, resilience characteristics are essential to effectively cope with change, and the best predictor of adjustment to the new environment among international students (Wang, 2017). In this regard, Tusaie and Dyer (2004) expressed that resilient students could cope with the difficulties inherent in moving to a university in a foreign country, and succeed academically. Moreover, numerous researches suggest that resilience can be reinforce because it is not a "hard-wired" personality trait; instead, it is the consequence of the advancement of protective factors (Zimmerman and Arunkumar, 1994). Many, empirical studies reveal that resilience varies across individuals, and may highly depend on many other psychological factors, such as optimism and psychological well-being (Poyrazli et al., 2004; Rosenthal et al., 2007; Yusoff and Chelliah, 2010; Sagone and De Caroli, 2014).

Based on the review of previous studies on the mediating role of self-efficacy in the relationship between resilience and its predicting factors (Au et al., 2009; Souri and Hasanirad, 2011; Hosseinchari and Ghasem, 2012; Cody, 2013; Manganelli et al., 2015; Yu et al., 2015; Woldgabreal et al., 2016), no empirical study has examined the mediating role of self-efficacy in the relationship between optimism, psychological well-being, and resilience among international students in Malaysia. Although some models of self-efficacy and resiliency have been proposed, none of these models combined all these factors in a single study, and it is not known how this model fits the data in Asian countries. Therefore, the gaps that this study discusses are related to the lack of a quantitative explanation of mediating role of self-efficacy and its related factors among international students in a public university in Malaysia.

The specific objectives of this study are as follows:

1. To investigate the relationship between optimism, dimensions of psychological well-being and resilience among Iranian students in UPM; and

2. To investigate the mediating effect of self-efficacy in the relationship between optimism, dimensions of psychological well-being and resilience among Iranian students in UPM.

The research framework of this study provides access to a range of topics in resilience and self-efficacy. For the theoretical background of this research, resilience model of Kumper in conjunction with the social cognitive theory (SCT) was used. The resilience model of Kumpfer incorporates the predictive factors and process of resilience, leading to successful life adaptation in people who show resiliency. The Kumpfer model tries to clarify the variables known to multiply the resilience into a dynamic frame that describes the connections between an individual with high resilience and the individual's highrisk context (Kumpfer, 2002).

To generate a classified framework to better understand personal factors related to resiliency, the internal individual factors are categorized into five main areas that may overlap: cognitive, emotional, social/behavioral, spiritual, and physical domains. The spiritual cluster of resiliency mainly involves cognitive competencies or belief structures. The variables are as follows: purpose in life, belief in uniqueness or oneself, independence, optimism, determination, and perseverance (Richardson et al., 1990). According to Kumpfer (2002), optimism is a cognitive factor, and highly resilient people apply optimistic characteristics to construct positive outcomes for themselves and others (Campbell et al., 1976; Murphy and Moriarty, 1976; Parker et al., 1990; Luthar and Zigler, 1991; Werner and Smith, 1992). A self-efficacy cycle comprises several successes developed by creating small steps with an excellent chance for success. Increasingly resilient youths are partial toward an "optimistic bias" and "latch on to any excuse for hope and faith in recovery" (Murphy, 1987). Other cognitive traits or processes that affect stimulate resilient people to positive success are believers in themselves and their specialness or uniqueness (Gordon and Song, 1994). Gordon and Song (1994) stated that achieving success despite all difficulties was related to autonomous selfdirectedness in resilient people. The authors described such individuals as autonomous/maverick selves who could resist social pressures and prefer to participate in goal-directed activities. The existential meaning and having a goal in life help resilient people pass through difficulties and become survivors because they have faith in achieving their goals (Richardson et al., 1990).

To succeed in their selected direction or mission, resilient persons are determined and perseverant in their cognitive style (Werner, 1985; Bandura, 1989). Life skills, practicality, talents, and competencies are necessary coping skills that help them 
reach their aims (Garmezy and Masten, 1986). Although determination and long-term planning skills are significant factors that help resilient people get their direction or mission, generating alternative or new plans and showing flexibility in planning are also essential aspects of resilient people (Bandura, 1989). Although behavioral and social competencies are similar to cognitive competencies because they build on the latter, these social and behavioral abilities vary due to the need for a behavioral action instead of only thinking. The social and behavioral ability to cope with diverse environments is referred to as "street smart" (Flach, 1988; Wolin and Wolin, 2010) or "environmental mastery" (Ryff, 1989), which is known to be related to resilience. Resilient people have warm, satisfying, trusting relationships with others (Ryff, 1989), and they have a sense of responsibility for other people (Werner, 1985). They show empathy for the needs of others, and also care for others (Werner, 1985). These individuals are active and responsive in relations with other people, and extract more positive reactions from them (Demos, 1989).

The resilient individual's cognitive characteristics contain cognitive abilities that assist him/her in reaching his/her goals or dreams. Resilient young people can restore their resilient self-efficacy after disruption or failure in homeostasis (Bandura, 1977). Self-efficacy here is defined as the perceived ability to do a precise behavioral task (Bandura, 1977), perception of the effects of selecting challenges or duties, and emotional responses to the danger of failure (Lawrance and McLeroy, 1986). A youth who avoids testing challenges because of low self-esteem or self-efficacy will have a challenging time to improve his/her resilience (Schunk and Carbonari, 1984). Based on Bandura's theory, undertaking challenges or defeating stressors is required to improve of self-efficacy. Shy or overprotected youths may not learn to face challenges due to the restrictive opportunities to increase their competencies and self-efficacy. Bandura also stated that individuals who experience only easy successes expect fast outcomes, and failure can quickly weaken their sense of efficacy (Bandura, 1989).

Social cognitive theory (SCT) includes a psychological model of behavior resulted from Albert Bandura's effort (Bandura, 1986). Bandura (1986) improved the thinking concerning human functions to agree with the dominant role played by vicarious, cognitive, self-reflective, and self-regulatory processes in human change and adaptation. Based on this theoretical view, human functioning observes as an active interaction of environmental, behavioral, and personal effects. Among all the thoughts that stand at the very essence of social cognitive theory, and influence human functioning are self-efficacy beliefs: the judgment of individuals on their competencies to form and carry out actions to achieve a task. If individuals consider that their activities can yield the consequences they wish, they require little motivation to perform or deal with hardships. According to Bandura's SCT, human functioning depends on an active interaction of environmental, behavioral, and personal effects. Self-efficacy beliefs affect the individuals' choices and the sequences of acts that they follow. Furthermore, self-efficacy beliefs assist in regulating the extent of efforts individuals will exert to complete a task, the duration with which individuals face difficulties, and how they will confront the adverse circumstances. The highest sense of efficacy arises from the more significant effort, mastery, perseverance, motivation, and resilience (Bandura, 1989).

Individuals who have a greater sense of their competencies will approach difficult tasks as sophisticated challenges rather than threats to escape. They develop a better inherent concern and a profound obsession in their actions, tend to set themselves challenging aims, preserve a resilient commitment to these challenges, and increase and bear their efforts in the face of failure. Furthermore, they can recover their sense of efficacy more quickly after disappointments or obstacles, and attribute failure to inadequate action or a lack of information and abilities that they can acquire.

To achieve the objectives of the study, a conceptual framework is designed (Figure 1).

\section{LITERATURE REVIEW}

\section{Optimism, Psychological Well-Being, and Resilience}

Carver et al. (2010) stated that optimism tended to imagine positive consequences in the future. Furthermore, when optimists encountered challenging but potentially surmountable obstacles, they tried to address the problems and focus on their goals, coping with problem-solving and careful planning (Carver et al., 2010). Optimistic individuals are more likely to show resilience when facing challenging situations even

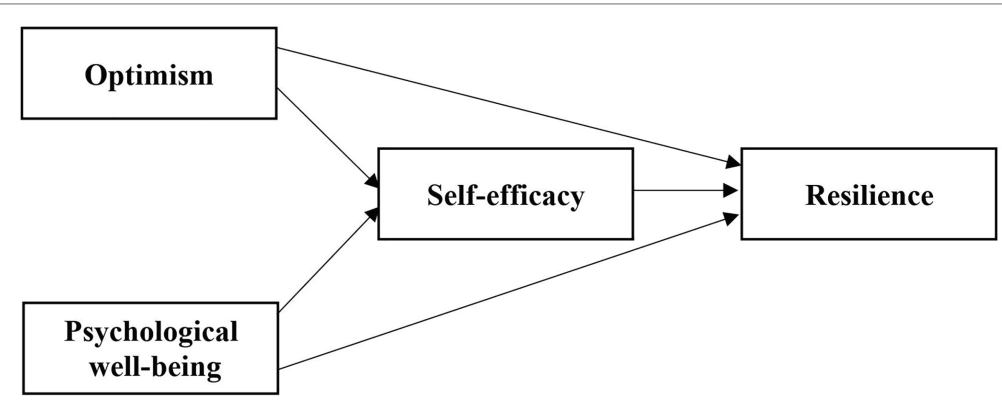

FIGURE 1 | Conceptual framework. 
though they might show slow progress (Snyder et al., 2002). Miranda and Cruz (2020) indicated that optimism helped students cope with challenges in college. Furthermore, Dawson and Pooley (2013) revealed that students experience higher resilience levels with higher optimism levels. Optimistic individuals are more resilient when facing challenges than less optimistic individuals (Kleiman et al., 2017; Gómez Molinero et al., 2018; Pathak and Lata, 2018).

Based on the review of past literature, Ryff and Singer (2003) revealed that resilient persons could protect their physical and psychological well-being, and bounce back from tense events. As Acciari et al. (2019) stated, the levels of resilience and psychological well-being were interrelated. Ryff and Singer (2003) believed that maintaining mental and physical health, and the ability to recover faster from stressors characterize resilient individuals. Coward and Reed (1996) defined psychological well-being as an individual's sensation of feeling healthy, resulting in a comprehensive consciousness of personal integrity that consisted of spiritual components of life. Previous studies indicated that psychological well-being (self-acceptance, environmental mastery, and personal growth) was significantly related to resilience (Keye and Pidgeon, 2013; Sagone and De Caroli, 2014).

Furthermore, a positive relationship between autonomy and resilience was revealed by Kaydkhorde et al. (2014). Based on Bernard (2014), environmental mastery, self-acceptance, and positive relation with others are significant resilience indicators. From this perspective the respondents perceived themselves as self-satisfied, and they were able to choose the contexts suitable for personal needs and see themselves as growing and expanding. Moreover, Picardi et al. (2012) reported a positive correlation between psychological well-being (except for the dimension of autonomy) and resilience.

H1: There is a significant relationship between optimism and resilience among Iranian students in UPM.

$\mathrm{H2}$ : There is a significant relationship between dimensions of psychological well-being and resilience among Iranian students in UPM.

\section{Self-Efficacy, Optimism, Psychological Well-Being, and Resilience}

The association between optimism, psychological well-being, and resilience has been confirmed several studies (Dawson and Pooley, 2013; Bernard, 2014; Sagone and De Caroli, 2014), but little is known about the mediators of this association. Building upon the psychological perspective (Bandura, 1986; Kumpfer, 2002), the research focuses on the role of self-efficacy, as mediator.

Cervone (2004) proposed a new cognitive model of personality; in the model, self-efficacy represents knowledge about one's abilities, which results in the appraisal of the future as positive (optimism), subsequently leading to good mental health. Karademas (2006) pointed out that high self-efficacy enhanced optimism and, subsequently, leads to better mental health; thus, optimism has been found to play a mediating role in the relationship between self-efficacy and depression
(Karademas, 2006; Pu et al., 2016). Furthermore, the previous rationale and available literature showing that optimism contributes to self-efficacy (Karademas, 2006; Lee et al., 2006; $\mathrm{Pu}$ et al., 2016), and self-efficacy contributes to resilience (Speight, 2009; Keye and Pidgeon, 2013).

High self-efficacy is related to better well-being, and low self-efficacy is related to lower well-being levels (Caprara, 2002; Bandura et al., 2003). Significantly, positive relationships between psychological well-being and self-efficacy have also been reported (Bahadori Khosroshahi and Hashemi Nosrat Abad, 2012). Similarly, a significant positive relationship between academic self-efficacy and psychological well-being has also been observed (Asghari et al., 2014; Priesack and Alcock, 2015). Koller and Hicks (2016) found that mental health professionals in Australia would show higher psychological capital levels (self-efficacy, optimism, hope, and resilience). Moreover, they reported that this group showed higher psychological well-being levels (autonomy, environmental mastery, personal growth, relationship to others, purpose in life, self-acceptance).

Additionally, according to Choi et al. (2016), mastery experience is a prominent predictor of school principals' selfefficacy in dealing with bullying among students in secondary schools. This result is in line with Bandura's (1977) findings, which show that mastery experience is the essential determinant of self-efficacy. One of the inseparable components of the autonomy of students is their self-efficacy beliefs. Bandura (1982) declared that learners' self-efficacy determined their performance since it affected their thoughts and motivation. Mojoudi and Tabatabaei (2014) revealed a relatively high correlation between upper intermediate students' self-efficacy and autonomy, suggesting that boosting upper intermediate student's self-efficacy will result in a considerable upturn in their autonomy.

Additionally, Tilfarlioglu and Ciftci (2011) found a positive correlation between self-efficacy and autonomy among students. Sanadgol (2015) investigated the relationship between selfacceptance and self-efficacy among high school students in Zahedan. The results supported the importance of self-acceptance as a predictor of self-efficacy. The sense of purpose in life has a significant meaning for well-being and self-efficacy. DeWitz et al. (2009) found a significantly positive correlation between self-efficacy and purpose in life. Çelik (2015) confirmed that the student academic support and academic self-efficacy are significantly correlated with personal growth initiative.

Hosseinchari and Ghasem (2012) demonstrated that intrinsicextrinsic motivation could predict psychological resilience mediated by self-efficacy and stress appraisal. Similarly, a study of undergraduate students of Southeastern University in the United States discovered the mediating role of self-efficacy in a relationship between negative life changes and resilience (Cody, 2013). According to Hudson (2007), self-efficacy and parental engagements are two significant predictors of college students' academic success and resilience. Hamill (2003) investigated self-efficacy, response to stress, perceptions of control, persistence, and coping mechanisms among maladaptive students and resilient students. The results indicated that selfefficacy and the capacity to articulate coping were two essential 
characteristics that distinguished the resilient group of the maladaptive youths, as predicted.

H3: There is a relationship between optimism and resilience among Iranian students in UPM when selfefficacy is mediated.

H4: There is a relationship between psychological wellbeing and resilience among Iranian students in UPM when self-efficacy is mediated.

\section{MATERIALS AND METHODS}

\section{Population, Sample Size, and Sampling Procedure}

The population of this study is 841 Iranian students of UPM. The research employed GPower (version 3.1), with a significance level of 0.05 , power of 0.80 , and medium effect size $(r=0.30)$ to calculate the appropriate sample size. However, the study included a greater number of subjects to ensure the study's reliability to counter the possibility of the nonresponse error. Indeed, for data collection procedures like surveys and other voluntary participation methods, the response rates are typically less than $100 \%$. Therefore, oversampling was suggested by increasing the sample size for uncooperative subjects (Salkind and Rainwater, 2006). Additionally, Krejcie and Morgan (1970) indicated that to be more confident with the selected sample, acquiring a bigger sample than the numbers shown in their table of sample size is recommended.

Therefore, 400 samples out of 841 samples were selected from a sample frame of all Iranian students in UPM using a simple random sampling technique. Later, the researcher provided an online questionnaire form and emailed it to the targeted respondents. A total of 265 questionnaires were returned, out of which 251 questionnaires were filled appropriately for analysis in this study. Table 1 shows the distribution of the frequency and percentage by gender and marital status of the 251 respondents participated in this study. According to the results, 134 males (53.4\%) and 117 females (46.6\%) participated in this study. More than half of the respondents, $61.4 \%$ $(N=154)$, were single, and $38.6 \%(N=97)$ were married.

\section{Measures}

To measure the variables of the study, four questionnaires were used. To measure resilience, the Connor-Davidson Resilience (CD-RISC) scale (Connor and Davidson, 2003), attempts to identify subjects' capability in effectively dealing

TABLE 1 | Profile of sample.

\begin{tabular}{lcc}
\hline Variables $(\boldsymbol{n}=\mathbf{2 9 1})$ & Frequency & Percentage (\%) \\
\hline Male & 134 & 53.4 \\
Female & 117 & 46.6 \\
Single & 154 & 61.4 \\
Married & 97 & 38.6 \\
Total & 251 & 100
\end{tabular}

with stress and adversity was employed. The life orientation test - revised (LOT-R) was adopted from Scheier and Carver (1985) to assess optimism. LOT-R generalizes the outcome expectations and assumptions as stressed by Scheier and Carver's optimism theory (Snyder et al., 2003). The General Self-Efficacy scale (Schwarzer and Jerusalem, 1995) was used to measure self-efficacy by predicting coping with daily stresses and adaptation after experiencing all kinds of stressful life events. To assess students' psychological well-being, the Ryff Psychological Well-being scale was employed. The Ryff Psychological Well-Being scales was organized by Abbott et al. (2010) as a multidimensional concept to be a straightforward and relatively short survey that measures the psychological component of well-being.

\section{Data Characteristics}

Preliminary analysis is an initial process at the beginning of a study to ensure the dataset is normally distributed. In this study, the preliminary analysis involved univariate normality and collinearity analysis. Kline (2015) suggested that the univariate normality of an item was achieved if the item's skewness and kurtosis values range between -1.96 and +1.96. The results indicated that all the variables' dimensions achieved the univariate normality (skewness and kurtosis values ranged from -1.193 to 1.177$)$. Next, the collinearity diagnostic analysis was performed. According to Norusis (2012), the possibility of multicolinearity is low if the value of Tolerance is more than 0.1 while the value of VIF is less than 10.00. The value of Tolerance (range between 0.28 and 0.61 ) and variance inflation factor (range between 1.64 and 3.52) the requirement as recommended by Norusis (2012), indicating that the collinearity was not a severe issue in the present model.

\section{Confirmatory Factor Analysis}

Confirmatory factor analysis (CFA) is a procedure to assess the measurement model by examining the relationship between observed variables and latent constructs (Brown, 2015). The CFA includes assessing factor loading, fit indices, and construct validity (e.g., convergent validity and discriminant validity). In general, factor loadings of 0.70 and above are considered satisfactory (Hair, 2010) and a factor loading of 0.6 is also suggested as acceptable (Chin et al., 1997). According to Table 2, after eliminating items with low factor loadings - less than 0.60 - the factor loadings for the remaining items ranged from 0.66 to 0.90 .

\section{Validity and Reliability}

Convergent validity $(\mathrm{CV})$ refers to the degree to which multiple items to measure the same concept agree (Hair et al., 2006). $\mathrm{CV}$ can be assessed through the average variance extracted (AVE) value. An AVE value of 0.5 confirms the $\mathrm{CV}$ of the construct. As shown in Table 2, the results indicated that the AVE for all variables exceeded the cut-off value of 0.05 - psychological well-being (0.734), optimism (0.524), and resilience $(0.542)$ - thus, indicating that the constructs explained 
most of the variance (Hair, 2010). Furthermore, construct reliability was assessed to confirm the measures' internal consistency through composite reliability (CR). A CR value of 0.7 and above proved that this study's measures possessed satisfactory internal consistency reliability. The results of composite reliability showed that all constructs had achieved the standard criterion of psychological well-being (0.892),

TABLE 2 | Results of measurement model assessment.

\begin{tabular}{|c|c|c|c|c|}
\hline Construct & Item & Loadings & CR & AVE \\
\hline $\begin{array}{l}\text { Psychological } \\
\text { well-being }\end{array}$ & $\begin{array}{l}\text { PL01 } \\
\text { PL03 } \\
\text { PL10 } \\
\text { EN05 } \\
\text { EN08 } \\
\text { EN09 } \\
\text { PG11 } \\
\text { PG12 } \\
\text { PG14 } \\
\text { PR06 } \\
\text { PR13 } \\
\text { PR16 } \\
\text { AU15 } \\
\text { AU17 } \\
\text { AU18 } \\
\text { SA02 } \\
\text { SA04 } \\
\text { SA07 }\end{array}$ & $\begin{array}{l}0.761 \\
0.844 \\
0.759 \\
0.867 \\
0.825 \\
0.711 \\
0.774 \\
0.800 \\
0.822 \\
0.753 \\
0.761 \\
0.801 \\
0.754 \\
0.822 \\
0.885 \\
0.912 \\
0.796 \\
0.633\end{array}$ & 0.892 & 0.734 \\
\hline Optimism & $\begin{array}{l}\text { OP01 } \\
\text { OP02 } \\
\text { OP03 } \\
\text { OP05 } \\
\text { OP07 }\end{array}$ & $\begin{array}{l}0.704 \\
0.794 \\
0.710 \\
0.646 \\
0.707\end{array}$ & 0.868 & 0.524 \\
\hline Resilience & $\begin{array}{l}\text { R01 } \\
\text { R05 } \\
\text { R09 } \\
\text { R11 } \\
\text { R12 } \\
\text { R14 } \\
\text { R15 } \\
\text { R16 } \\
\text { R17 } \\
\text { R18 } \\
\text { R19 } \\
\text { R24 } \\
\text { R25 }\end{array}$ & $\begin{array}{l}0.778 \\
0.729 \\
0.692 \\
0.651 \\
0.767 \\
0.764 \\
0.762 \\
0.728 \\
0.865 \\
0.813 \\
0.765 \\
0.907 \\
0.820\end{array}$ & 0.892 & 0.542 \\
\hline
\end{tabular}

optimism (0.868), and resilience (0.892), indicating high consistency reliability of the instrument.

Besides that, Fornell and Larcker (1981) approach was used to assess the constructs' discriminant validity. Discriminant validity ensures that a construct is genuinely distinct from other constructs in the model. The square root of AVE was compared with the correlations of latent variables. As a rule of thumb, AVE's square must be greater than the correlation value of any other construct in the model (Fornell and Larcker, 1981). As shown in Table 3, the square root of AVE all constructs (diagonal values) was higher than the correlations values in the rows and column, suggesting that the measurement model had enough discriminant validity.

\section{Data Analysis}

A two-stage structural equation modeling approach was employed to analyze the research model (Hair, 2010). The Analysis of Moment Structures (IBM AMOS) version 22 was used to test the hypothesized model.

\section{RESULTS}

The mediating effects of self-efficacy were assessed through path analysis. The full mediation structural model is displayed in Figure 2. The results of the full mediation structural model fit indicated that the model fit the data well, with Chi-square $=877.064, p=0.000$, Relative Chi-Sq $=1.683$; GFI $=0.823$, CFI $=0.917$, IFI $=0.918$, RMSEA $=0.052$. The Goodnessof-fit indices of the structural model indicated that the GFI, CFI, and IFI approached or exceeded the cut-off value of 0.90 (Hair, 2010). Moreover, the RMSEA was 0.052, falling within the recommended range between 0.03 and 0.08 (Hair, 2010).

The regression weight of the total effect showed a significant impact of psychological well-being on resilience, and the insignificant impact of optimism on resilience (Table 4). In the next step, the bootstrapping procedure was conducted to test the mediation effects. Therefore, Bias-Corrected Confidence Interval (CI) was performed with a 95\% confidence level and 5000 bootstraps. The outcomes of the bootstrap approximation were obtained by constructing two-sided bias-corrected confidence intervals. Table 5 indicates that the direct model (linking all dimensions of psychological well-being to resilience) showed a statistically significant effect $(\beta=0.549, p<0.000)$.

TABLE 3 | Results of measurement model assessment.

\begin{tabular}{|c|c|c|c|c|c|c|c|c|c|}
\hline & 1 & 2 & 3 & 4 & 5 & 6 & 7 & 8 & 9 \\
\hline 1. Resilience & 0.680 & & & & & & & & \\
\hline 2. Self-efficacy & 0.592 & 0.738 & & & & & & & \\
\hline 4. Purpose in life & 0.353 & 0.442 & 0.157 & 0.775 & & & & & \\
\hline 5. Environmental & -0.060 & 0.083 & 0.179 & 0.152 & 0.793 & & & & \\
\hline 6. Positive relation & 0.417 & 0.438 & 0.065 & 0.313 & 0.127 & 0.762 & & & \\
\hline 9. Optimism & 0.583 & 0.531 & -0.103 & 0.245 & 0.048 & 0.433 & 0.536 & 0.188 & 0.784 \\
\hline
\end{tabular}

The bold values are the relationship values. 


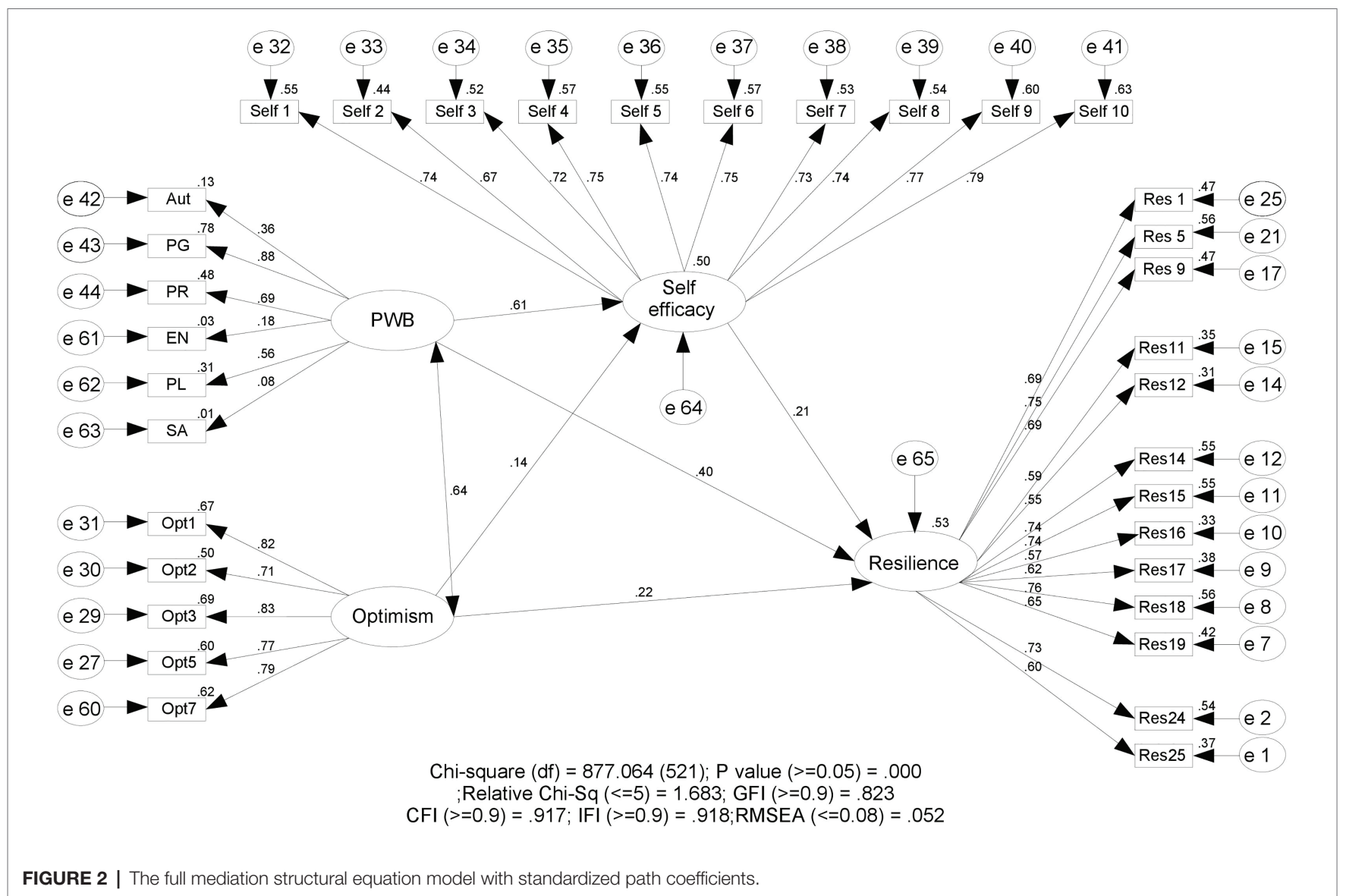

TABLE 4 | Regression weight for the total effect.

\begin{tabular}{lccccc}
\hline Hypothesized relationship & B & $\boldsymbol{\beta}$ & S.E. & CR & $\boldsymbol{p}$-value \\
\hline PWB -> Resilience & 1.036 & 0.549 & 0.254 & 4.074 & 0.000 \\
Optimism -> Resilience & 0.188 & 0.238 & 0.060 & 3.125 & 0.003 \\
\hline
\end{tabular}

TABLE 5 | Results of bootstrap analysis.

\begin{tabular}{lcccc}
\hline Hypothesis path & B & P & \multicolumn{2}{c}{$\mathbf{9 5 \%} \mathbf{~ B C ~ b o o t s t r a p ~ C l ~}$} \\
\cline { 5 - 5 } & & & LB & UP \\
\hline Direct model & & & & \\
PWB -> Resilience & 0.549 & 0.000 & & \\
Optimism -> Resilience & 0.238 & 0.003 & & \\
Full mediation model & & & & \\
PWB -> Resilience & 0.421 & 0.000 & & \\
Std. indirect effects (SIE) & 0.000 & 0.008 & 0.044 & 0.262 \\
Optimism -> resilience & 0.204 & 0.007 & & \\
Std. indirect effects (SIE) & 0.030 & 0.150 & -0.010 & 0.107 \\
\hline
\end{tabular}

Moreover, the full mediation model (linking all dimensions of psychological well-being to resilience through self-efficacy) had a significant effect $(\beta=0.421, p<0.000)$. The indirect impact of environmental mastery, autonomy, self-acceptance, positive relations with others, personal growth, and purpose in life on resilience was also significant. Furthermore, the direct model (linking optimism to resilience) was not statistically significant $(\beta=0.238, p<0.000)$.

According to Table 5, zero is not within the range of lower and upper bounds. Therefore, based on the decision criteria, self-efficacy mediated the influence of environmental mastery, autonomy, self-acceptance, positive relations with others, personal growth, and purpose in life on resilience. Besides that, based on the decision criteria, self-efficacy did not mediate the influence of optimism on resilience.

\section{DISCUSSION}

This study examined the relationship between optimism, components of psychological well-being, and resilience among Iranian students in Universiti Putra Malaysia. Furthermore, the study assessed the mediating effect of self-efficacy on the relationship between optimism, components of psychological 
well-being, and resilience among Iranian students in Universiti Putra Malaysia.

The results showed a significant relationship between optimism, components of psychological well-being, and resilience, supporting hypotheses 1 and 2. The findings are in line with some other studies that observe the relationship between optimism, components of physiological well-being, and resilience (Agarwal and Malhotra, 2019; Bano and Pervaiz, 2020; Maheshwari and Jutta, 2020). It seems there is an interactive relationship between optimism, psychological well-being, and resilience. As the findings illustrate, students having a positive attitude are more likely to control their surroundings, and greater faith in their ability to respond to and resolve obstacles. In other words, positive attitudes about life and future improve resilience or the willingness to deal with hardship and difficult circumstances.

Furthermore, the findings revealed that in terms of shaping students' perspectives on life issues, and their ability to handle and cope with problems, components of psychological wellbeing play an important role. This means that Iranian students seem to be self-satisfied; they can make relevant associations for their needs, and they see themselves as growing and expanding. Besides that, the students may have purposes and ambitions in their lives, such as being imaginative and efficient or achieving emotional integration later in life, both of which influence how they cope with challenging circumstances. The dimensions of psychological well-being affect the students' perspectives on life issues, and their capability to manage and cope with challenges in their life (Smith and Yang, 2017; Chow et al., 2018).

The study's finding well-supported H4, showing self-efficacy's mediating role in the relationship between dimensions of psychological well-being (environmental mastery, autonomy, self-acceptance, positive relations with others, personal growth, and purpose in life) and resilience. The findings are consistent with the previous studies, confirming the relationship between psychological well-being, self-efficacy, and resilience, as well as the mediating role of self-efficacy (DeWitz et al., 2009; Tilfarlioglu and Ciftci, 2011; Mojoudi and Tabatabaei, 2014; Çelik, 2015; Sanadgol, 2015; Choi et al., 2016; Koller and Hicks, 2016; Ngui and Lay, 2017; Develos-Sacdalan and Bozkus, 2018; Wang et al., 2018; Roohi et al., 2019; Vongsirimas et al., 2020).

The findings can explain that the components of psychological well-being are related to self-efficacy, which would enhance resilience. It seems that the students' belief in their ability has a significant effect on the students' capability to maintain psychological and physical health and the ability to adjust to difficulties in the host country. Understanding this result is by considering the concept of self-efficacy as an adaptive mechanism, which refers to students' belief in their capability to fulfill tasks to achieve their goals. In this respect, through educational programs, students' self-efficacy can improve, which has a significant role in increasing psychological well-being and resilience.

\section{Implication}

Theoretically, consistent with Kumpfer's (2002) and Bandura's (1986) findings, this study supported the notion of a relationship between optimism, dimensions of psychological well-being, self-efficacy, and resilience. This study has conducted a comprehensive review based on the theory and constructs that are less explored in this topic's research theory. The result have led to the development of a new model of variables that contribute to resilience with the mediating role of self-efficacy among Iranian students. The model provides complete knowledge of the topic while simplifying the understanding of the situation for both researchers and practitioners. This research is a systematic attempt to contribute to a deeper understanding of these theories, although there is still room to improve and add more knowledge to this stream.

Practically, the research on self-efficacy and resilience has revealed that there has been a tendency for the psychology discipline to neglect crucial human adaptation and development. It instead focuses on potential; this approach should change. Hopefully, the findings of this study provide an overview of the challenges faced by Iranian students, and support them accordingly. The notion of self-efficacy and resilience has significant implications in educational psychology in five main domains: assessment, intervention, consultation, research, and training. Since self-efficacy and resilience, and their related factors can be learned and taught as a skill, the authorities in charge of international students in universities and organizations are responsible for regulating the policies to enhance students' ability to deal with the challenges. Therefore, related informative workshops and seminars should improve students' knowledge and understanding concerning self-efficacy, resilience, and relevant factors. In this respect, there are various projects and strategies available to develop, nurture and teach skills. For instance, self-efficacy training for international students (SETIS) is based on social cognitive theory, which is adequate in describing this phenomenon and recommending strategies to improve students' self-efficacy. The implementation of SETIS meets a standard procedure for performing successful training, including a need assessment and a post-training assessment. Moreover, a training program called the Road to Resilience developed by American Psychological Association trains students to build resilience or "strengthen the mental muscle that everyone has," using "bounce back" strategies. These may include: have a friend and be a friend, set new goals and plan to reach them, take charge of your behavior, look on the bright side, and believe in yourself.

Understanding the strategies to develop self-efficacy and resiliency as skills would help international students to reduce the time required for the adjustment process. For example, Bandura (1977) indicated, self-efficacy beliefs were created when students perceive knowledge from four main sources. (1) Mastery Experience: the way students perceive and analyze obtained outcomes, as well as how these interpretations were used to update and establish self-beliefs of competence. (2) Vicarious Experiences of observing others: seeing or hearing similar individuals achieve success encourages students to feel that if others can do it, so can they. (3) Modeling Experiences: those are the people students look up to, respect, and aspire to be like. Their deeds, values, and accomplishments teach and persuade students to do the same. (4) Emotional and Physical Experiences: self-efficacy is strongly affected by student's mental 
and physical states. Positive experiences and happiness make students feel good about themselves. In contrast, negative experiences and tension make students feel insecure. Students should be aware of the strategies to enhance their self-efficacy and apply them in their lifestyle and attitude. This study demonstrates the self-efficacy and resilience pattern to help alleviate some of the students' challenges and social-emotional adjustment. The awareness can encourage students to successfully deal with unfamiliar situations throughout not only their education, but also their life.

Besides that, it is necessary for counselors, educators, and professionals to consider the evidence obtained from the current study to design self-efficacy and resilience enhancement programs for international students. Hence, these findings can help to increase the availability of the program through counseling services. Appropriate counseling opportunities should be given to international students facing difficulties adjusting to new situations. Moreover, the findings can be used as a resource material for researchers, scientists, and university authorities. This study also opens the doors for further research on self-efficacy and resilience, and its related factors to discover new findings that could be generalized to all international students.

\section{Limitation and Future Suggestions}

In the future, applying more qualitative and longitudinal researches could help to investigate how instructional strategies can be implemented to promote international students'

\section{REFERENCES}

Abbott, R. A., Ploubidis, G. B., Huppert, F. A., Kuh, D., and Croudace, T. J. (2010). An evaluation of the precision of measurement of Ryff's psychological well-being scales in a population sample. Soc. Indic. Res. 97, 357-373. doi: 10.1007/s11205-009-9506-X

Acciari, A. S., Leal, R. F., Coy, C. S. R., Dias, C. C., and Ayrizono, M. D. L. S. (2019). Relationship among psychological well-being, resilience and coping with social and clinical features in Crohn's disease patients. Arq. Gastroenterol. 56, 131-140. doi: 10.1590/s0004-2803.201900000-27

Agarwal, N., and Malhotra, M. (2019). Relationship between optimism, resilience and psychological well-being in young adults. Int. J. Soc. Sci. Econ. Res. 4, 6141-6148.

Asghari, F., Saadat, S., Atefi Karajvandani, S., and Janalizadeh Kokaneh, S. (2014). The relationship between academic self-efficacy and psychological well-being, family cohesion, and spiritual health among students of Kharazmi university. Iranian J. Med. Educ. 14, 581-593.

Au, A., Lai, M. K., Lau, K. M., Pan, P. C., Lam, L., Thompson, L., et al. (2009). Social support and well-being in dementia family caregivers: the mediating role of self-efficacy. Aging Ment. Health 13, 761-768. doi: 10.1080/136078609029 18223

Bahadori Khosroshahi, J., and Hashemi Nosrat Abad, T. (2012). The relationship between social anxiety, optimism, and self-efficacy with psychological wellbeing in students. Urmia Med. J. 23, 115-122.

Bandura, A. (1977). Self-efficacy: toward a unifying theory of behavioral change. Psychol. Rev. 84, 191-215. doi: 10.1037/0033-295X.84.2.191

Bandura, A. (1982). Self-efficacy mechanism in human agency. Am. Psychol. 37:122. doi: 10.1037/0003-066X.37.2.122

Bandura, A. (1986). The explanatory and predictive scope of self-efficacy theory. J. Soc. Clin. Psychol. 4, 359-373. doi: 10.1521/jscp.1986.4.3.359

Bandura, A. (1989). Human agency in social cognitive theory. Am. Psychol. 44:1175. doi: 10.1037/0003-066X.44.9.1175 self-efficacy and resilience. The findings may be more generalizable by recruiting a more comprehensive sample size from different nationalities in future studies.

\section{DATA AVAILABILITY STATEMENT}

The data that support the findings of this study are available from the first author upon reasonable request. Requests to access the datasets should be directed to f.sabouripour@gmx.de.

\section{ETHICS STATEMENT}

The studies involving human participants were reviewed and approved by Graduated Student Office, Universiti Putra Malaysia. The patients/participants provided their written informed consent to participate in this study.

\section{AUTHOR CONTRIBUTIONS}

We declare that all authors have made substantial contributions. FS was in charge of the conceptualization, investigation, methodology, writing original the draft, editing, and formatting the paper. SR was supervising the study. ZG was involved in the methodology and formal analysis. MAM was involved in the formal analysis. All authors approved the submitted version.

Bandura, A., Caprara, G. V., Barbaranelli, C., Gerbino, M., and Pastorelli, C. (2003). Role of affective self-regulatory efficacy in diverse spheres of psychosocial functioning. Child Dev. 74, 769-782. doi: 10.1111/1467-8624.00567

Bano, Z., and Pervaiz, S. (2020). The relationship between resilience, emotional intelligence and their influence on psychological well-being: a study with medical students. Pakistan Armed Forces Med. J. 70, 390-394.

Bartimote-Aufflick, K., Bridgeman, A., Walker, R., Sharma, M., and Smith, L. (2016). The study, evaluation, and improvement of university student selfefficacy. Stud. High. Educ. 11, 1918-1942. doi: 10.1080/03075079.2014.999319

Bernard, M. E. (2014). The Strength of Self-Acceptance: Theory, Practice and Research. 2nd Edn. New York, NY: Springer Science and Business Media.

Brown, T. A. (2015). Confirmatory Factor Analysis for Applied Research. 2nd Edn. London: The Guilford Press.

Campbell, A., Converse, P. E., and Rodgers, W. L. (1976). The Quality of American Life: Perceptions, Evaluations, and Satisfactions. 2nd Edn. New York, NY: Russell Sage Foundation.

Caprara, G. V. (2002). "Personality psychology: filling the gap between basic processes and molar functioning," in Psychology at the Turn of the Millennium. Vol. 2. eds. L. Backman and C. Hofsten (Taylor \& Francis/Routledge), 201-224.

Carver, C. S., Scheier, M. F., and Segerstrom, S. C. (2010). Optimism. Clin. Psychol. Rev. 30, 879-889. doi: 10.1016/j.cpr.2010.01.006

Çelik, E. (2015). Mediating and moderating role of academic self-efficacy in the relationship between student academic support and personal growth initiative. Aust. J. Career Dev. 24, 105-113. doi: 10.1177/10384162155 83563

Cervone, D. (2004). The architecture of personality. Studia Universitatis BabesBolyai-Psychologia-Paedagogia 1, 3-44.

Chang, Y., and Edwards, J. K. (2015). Examining the relationships among self-efficacy, coping, and job satisfaction using social career cognitive theory: an SEM analysis. J. Career Assess. 23, 35-47. doi: 10.1177/10690727145 23083 
Chin, W. W., Gopal, A., and Salisbury, W. D. (1997). Advancing the theory of adaptive structuration: the development of a scale to measure faithfulness of appropriation. Inf. Syst. Res. 8, 342-367. doi: 10.1287/isre.8.4.342

Choi, L. J., Syawal, N. B. A. R. M., and Narawi, B. (2016). Bullying cases among students: school principals' self-efficacy. Acad. Soc. Sci. J. 1, 143-167.

Chow, K. M., Tang, W. K., Chan, W. H., Sit, W. H., Choi, K. C., and Sally, C. H. (2018). Resilience and well-being of university nursing students in Hong Kong: a cross-sectional study. BMC Med. Educ. 18, 1-8. doi: 10.1186/s12909-018-1119-0

Cody, J. A.. (2013). The Roles of Stress Appraisal and Self-Efficacy in Fostering Resilience to Improve Psychosocial Outcomes Following Negative Life Events Among College Students: A Multiple Mediation Analysis. [doctoral dissertation]. [United States]: University of Tennessee - Knoxville.

Connor, K. M., and Davidson, J. R. (2003). Development of a new resilience scale: the Connor-Davidson resilience scale (CD-RISC). Depress. Anxiety 18, 76-82. doi: 10.1002/da.10113

Coward, D. D., and Reed, P. G. (1996). Self-transcendence: a resource for healing at the end of life. Issues Ment. Health Nurs. 17, 275-288.

Dawson, M., and Pooley, J. A. (2013). Resilience: the role of optimism, perceived parental autonomy support and perceived social support in first year university students. J. Educ. Train. Stud. 1, 38-49. doi: 10.11114/jets.v1i2.137

Demos, E. (1989). Philadelphia: Resiliency in Infancy. United States: Random House.

Denovan, A., and Macaskill, A. (2017). Stress and subjective well-being among first year UK undergraduate students. J. Happiness Stud. 2, 505-525. doi: 10.1007/s10902-016-9736-y

Develos-Sacdalan, K., and Bozkus, K. (2018). The mediator role of resilience between self-determination and self-efficacy. Online Submission 4, 49-60.

DeWitz, S. J., Woolsey, M. L., and Walsh, W. B. (2009). College student retention: an exploration of the relationship between self-efficacy beliefs and purpose in life among college students. J. Coll. Stud. Dev. 50, 19-34. doi: 10.1353/csd.0.0049

Flach, F. (1988). Resilience: Discovering a New Strength at Times of Stress. 2nd Edn. New York: Fawcett Books.

Fornell, C., and Larcker, D. F. (1981). Evaluating structural equation models with unobservable variables and measurment errors. J. Mark. Res. 18, 39-50. doi: $10.1177 / 002224378101800104$

Garmezy, N., and Masten, A. S. (1986). Stress, competence, and resilience: common frontiers for therapist and psychopathologist. Behav. Ther. 17, 500-521. doi: 10.1016/S0005-7894(86)80091-0

Gómez Molinero, R., Zayas, A., Ruiz González, P., and Guil, R. (2018). Optimism and resilience among university students. Int. J. Dev. Educ. Psychol. 1, 147-154. doi: 10.17060/ijodaep.2018.n1.v1.1179

Gordon, E. W., and Song, L. D. (1994). "Variations in the experience of resilience" in Educational Resilience in Inner-City America: Challenges and Prospects. Vol. 22. eds. M. C. Wang and E. W. Gordon (Hillsdale, NJ: Erlbaum), 27-43.

Hair, J. F. (2010). Multivariate Data Analysis: A Global Perspective. 2nd Edn. Vol. 7. Upper Saddle River, NJ: Pearson, 68-76.

Hair, J. F., Black, W. C., Babin, B. J., Anderson, R. E., and Tatham, R. (2006). SEM: confirmatory factor analysis. 4th Edn. Vol 6. Uppersaddle River, NJ, United States, 770-842.

Hamill, S. K. (2003). Resilience and self-efficacy: the importance of efficacy beliefs and coping mechanisms in resilient adolescents. Colgate Univ. J. Sci. 35, 115-146.

Hosseinchari, M., and Ghasem, M. (2012). Psychological resilience and intrinsicextrinsic motivation: the mediating role of self-efficacy. J. Iranian Psychol. 9:33.

Hudson, W. E.. (2007). The Relationship Between Academic Self-Efficacy and Resilience to Grades of Students Admitted Under Special Criteria. [doctoral dissertation]. [United States]: Florida State University, Florida.

Karademas, E. C. (2006). Self-efficacy, social support and well-being: the mediating role of optimism. Personal. Individ. Differ. 40, 1281-1290. doi: 10.1016/j. paid.2005.10.019

Kaydkhorde, H., Moltafet, G., and Chinaveh, M. (2014). Relationship between satisfying psychological needs and resilience in high-school students in Dezful town. Acad. J. Psychol. Stud. 3, 57-62.

Keye, M. D., and Pidgeon, A. M. (2013). Investigation of the relationship between resilience, mindfulness, and academic self-efficacy. Open J. Soc. Sci. 1, 1-12. doi: 10.4236/jss.2013.16001

Kleiman, E. M., Chiara, A. M., Liu, R. T., Jager-Hyman, S. G., Choi, J. Y., and Alloy, L. B. (2017). Optimism and well-being: a prospective multimethod and multidimensional examination of optimism as a resilience factor following the occurrence of stressful life events. Cognit. Emot. 31, 269-283. doi: $10.1080 / 02699931.2015 .1108284$
Kline, R. B. (2015). Principles and Practice of Structural Equation Modeling. 2nd Edn. New York: Guilford publications.

Koller, S. L., and Hicks, R. E. (2016). Psychological capital qualities and psychological well-being in Australian mental health professionals. Int. J. Psychol. Stud. 8:41. doi: 10.5539/ijps.v8n2p41

Komarraju, M., and Nadler, D. (2013). Self-efficacy and academic achievement: why do implicit beliefs, goals, and effort regulation matter? Learn. Individ. Differ. 25, 67-72. doi: 10.1016/j.lindif.2013.01.005

Krejcie, R. V., and Morgan, D. W. (1970). Determining sample size for research activities. Educ. Psychol. Meas. 30, 607-610. doi: 10.1177/001316447003000308

Kumpfer, K. L. (2002). "Factors and processes contributing toresilience" in Resilience and Development. eds. M. D. Glantz and J. L. Johnson (New York: Springer), 179-224.

Lawrance, L., and McLeroy, K. R. (1986). Self-efficacy and health education. J. Sch. Health 56, 317-321. doi: 10.1111/j.1746-1561.1986.tb05761.x

Lee, V., Cohen, S. R., Edgar, L., Laizner, A. M., and Gagnon, A. J. (2006). Meaning-making intervention during breast or colorectal cancer treatment improves self-esteem, optimism, and self-efficacy. Soc. Sci. Med. 62, 3133-3145. doi: 10.1016/j.socscimed.2005.11.041

Lightsey, O. R. Jr. (2006). Resilience, meaning, and well-being. Couns. Psychol. 34, 96-107. doi: 10.1177/0011000005282369

Liu, C., and Li, H. (2018). Stressors and stressor appraisals: the moderating effect of task efficacy. J. Bus. Psychol. 33, 141-154. doi: 10.1007/ s10869-016-9483-4

Luthar, S. S., and Zigler, E. (1991). Vulnerability and competence: a review of research on resilience in childhood. Am. J. Orthopsychiatry 61, 6-22. doi: $10.1037 /$ h0079218

Maheshwari, A., and Jutta, M. V. (2020). Study of relationship between optimism and resilience in the times of COVID-19 among university students. Int. J. Indian Psychol. 8, 2349-3429. doi: 10.31219/osf.io/5a3gs

Manganelli, S., Lucidi, F., and Alivernini, F. (2015). Italian adolescents' civic engagement and open classroom climate: the mediating role of self-efficacy. J. Appl. Dev. Psychol. 41, 8-18. doi: 10.1016/j.appdev.2015.07.001

Mesidor, J. K., and Sly, K. F. (2016). Factors that contribute to the adjustment of international students. J. Int. Stud. 1, 262-282. doi: 10.32674/jis.v6i1.569

Miranda, J. O., and Cruz, R. N. C. (2020). Resilience mediates the relationship between optimism and well-being among Filipino university students. Curr. Psychol. 1, 1-10. doi: 10.1007/s12144-020-00806-0

Misra, R., Crist, M., and Burant, C. J. (2003). Relationships among life stress, social support, academic stressors, and reactions to stressors of international students in the United States. Int. J. Stress. Manag. 10:137. doi: 10.1037/1072-5245. 10.2.137

Mojoudi, A., and Tabatabaei, O. (2014). The relationship between self-efficacy beliefs and autonomy among Iranian intermediate and upper intermediate EFL learners. Int. J. Appl. Ling. English Lit. 3, 22-28. doi: 10.7575/aiac. ijalel.v.3n.6p. 22

Mori, S. C. (2000). Addressing the mental health concerns of international students. J. Couns. Dev. 78, 137-144. doi: 10.1002/j.1556-6676.2000.tb02571.x

Morton, S., Mergler, A., and Boman, P. (2014). Managing the Transition: The Role of Optimism and Self-Efficacy for First-Year Australian University Students. Aust. J. Guid. Couns. 1, 90-108. doi: 10.1017/jgc.2013.29

Murphy, L. B., and Moriarty, A. E. (1976). Vulnerability, Coping and Growth From Infancy to Adolescence. 2nd Edn. New Haven, CT: Yale U Press.

Murphy, L. B. (1987). "Further reflections on resilience" in The Invulnerable Child. Vol. 19. eds. E. J. Anthony and B. J. Cohler (Guilford Press), 84-105.

Ngui, G. K., and Lay, Y. F. (2017). The relationship between resilience and perceived practicum stress: the mediating role of self-efficacy. Sains Humanika 9, 1-4. doi: 10.11113/sh.v9n1-4.1123

Norusis, M. J. (2012). IBM SPSS Statistics 19: Guide to Data Analysis. 3rd Edn. Vol. 672. Upper Saddle River (NJ): Prentice Hall.

Parker, G. R., Cowen, E. L., Work, W. C., and Wyman, P. A. (1990). Test correlates of stress resilience among urban school children. J. Prim. Prev. 11, 19-35. doi: 10.1007/BF01324859

Pathak, R., and Lata, S. (2018). Optimism in relation to resilience and perceived stress. J. Psychosoc. Res. 13, 359-367. doi: 10.32381/jpr.2018.13.02.10

Picardi, A., Bartone, P. T., Querci, R., Bitetti, D., Tarsitani, L., Roselli, V., et al. (2012). Development and validation of the Italian version of the 15 -item dispositional resilience scale. Riv. Psichiatr. 47, 231-237. doi: 10.1708/1128. 12446 
Poyrazli, S., Kavanaugh, P. R., Baker, A., and Al-Timimi, N. (2004). Social support and demographic correlates of acculturative stress in international students. J. Coll. Couns. 7, 73-82. doi: 10.1002/j.2161-1882.2004.tb00261.x

Priesack, A., and Alcock, J. (2015). Well-being and self-efficacy in a sample of undergraduate nurse students: a small survey study. Nurse Educ. Today 35, 16-20. doi: 10.1016/j.nedt.2015.01.022

Pu, J., Hou, H., and Ma, R. (2016). Direct and indirect effects of self-efficacy on depression: the mediating role of dispositional optimism. Curr. Psychol. 36, 410-416. doi: 10.1007/s12144-016-9429-Z

Richardson, G. E., Neiger, B. L., Jensen, S., and Kumpfer, K. L. (1990). The resiliency model. Health Educ. 21, 33-39.

Roohi, S., Noroozi, H., and Yousefi Afrashteh, M. (2019). Mediating role of resilience and self-efficacy in the relationship between cognitive emotion regulation strategies and psychological well-being of Iranian students. Health Educ. Health Promot. 7, 183-190.

Rosenthal, D. A., Russell, J., and Thomson, G. (2007). Social connectedness among international students at an Australian university. Soc. Indic. Res. 84, 71-82. doi: 10.1007/s11205-006-9075-1

Ryff, C. D. (1989). Happiness is everything, or is it? Explorations on the meaning of psychological well-being. J. Pers. Soc. Psychol. 57, 1069-1081. doi: 10.1037/0022-3514.57.6.1069

Ryff, C. D., and Singer, B. (2003). "Flourishing under fire: resilience as a prototype of challenged thriving," in Flourishing: Positive Psychology and the Life Well-Lived. eds. C. L. M. Keyes and J. Haidt (Washington, DC: American Psychological Association), 15-36.

Sagone, E., and De Caroli, M. E. (2014). Relationships between psychological well-being and resilience in middle and late adolescents. Procedia Soc. Behav. Sci. 141, 881-887. doi: 10.1016/j.sbspro.2014.05.154

Salkind, N. J., and Rainwater, T. (2006). Exploring Research. 8th Edn. Pearson Prentice Hall, New Jersey, USA: Upper Saddle River.

Sanadgol, S. (2015). Predictive role of self-acceptance in self-efficacy of third grade high school students. Int. J. Rev. Life Sci. 3, 383-386.

Scheier, M. F., and Carver, C. S. (1985). Optimism, coping, and health: assessment and implications of generalized outcome expectancies. Health Psychol. 4, 219-247. doi: 10.1037/0278-6133.4.3.219

Schunk, D. H., and Carbonari, J. P. (1984). Self-Erficacy Models. Behavioral Health: A handbook of Health. Vol. 4. New York: Wiley, 230-247.

Schwarzer, R., and Jerusalem, M. (1995). "Generalized self-efficacy scale" in Measures in Health Psychology: A User's Portfolio. Causal and Control Beliefs. Vol. 1. eds. J. Wein-man, S. Wright and M. Johnston (Windsor: NFERNelson), 35-38.

Smith, G. D., and Yang, F. (2017). Stress, resilience and psychological wellbeing in Chinese undergraduate nursing students. Nurse Educ. Today 49, 90-95. doi: 10.1016/j.nedt.2016.10.004

Snyder, C. R., Feldman, D. B., Shorey, H. S., and Rand, K. L. (2002). Hopeful choices: a school counselor's guide to hope theory. J. Pers. Soc. Psychol. 65, 1061-1070.

Snyder, C. R., Lopez, S. J., Shorey, H. S., Rand, K. L., and Feldman, D. B. (2003). Hope theory, measurements, and applications to school psychology. Sch. Psychol. Q. 18:122. doi: 10.1521/scpq.18.2.122.21854

Souri, H., and Hasanirad, T. (2011). Relationship between resilience, optimism and psychological well-being in students of medicine. Procedia Soc. Behav. Sci. 30, 1541-1544. doi: 10.1016/j.sbspro.2011.10.299

Speight, N. P. (2009). The relationship between self-efficacy, resilience and academic achievement among African American urban adolescents. PhD dissertation. Howard University.

Takeuchi, D. T., Zane, N., Hong, S., Chae, D. H., Gong, F., Gee, G. C., et al. (2007). Immigration-related factors and mental disorders among Asian Americans. Am. J. Public Health 97, 84-90. doi: 10.2105/AJPH.2006.088401
Talebloo, B., and Baki, R. B. (2013). Challenges faced by international postgraduate students during their first year of studies. Int. J. Humanit. Soc. Sci. 13, 138-145.

Tilfarlioglu, F. Y., and Ciftci, F. S. (2011). Supporting self-efficacy and learner autonomy in relation to academic success in EFL classrooms. Theory Pract. Lang. Stud. 1, 1284-1294. doi: 10.4304/tpls.1.10.1284-1294

Titrek, O., Hashimi, S. H., Ali, S., and Nguluma, H. F. (2016). Challenges faced by international students in Turkey. Anthropologist 24, 148-156. doi: 10.1080/09720073.2016.11892000

Tusaie, K., and Dyer, J. (2004). Resilience: a historical review of the construct. Holist. Nurs. Pract. 18, 3-10. doi: 10.1097/00004650-200401000-00002

Villada, C., Hidalgo, V., Almela, M., and Salvador, A. (2017). Assessing performance on an evaluated speaking task. J. Psychophysiol. 32, 64-74. doi: 10.1027/0269-8803/a000185

Vongsirimas, N., Sitthimongkol, Y., Kaesornsamut, P., Thanoi, W., Pumpuang, W., Phetrasuwan, S., et al. (2020). Mediating role of mindfulness, self-efficacy, and resilience on the stress-psychological well-being in Thai adolescents. Int. J. Psychosoc. Rehabil. 24, 5376-5391.

Wang, J. (2017). Study of the Adjustment of International Graduate Students at American Universities, Including Both Resilience Characteristics and Traditional Background Factors. [doctoral dissertation]. [Florida, United States]: Florida State University.

Wang, L., Tao, H., Bowers, B. J., Brown, R., and Zhang, Y. (2018). Influence of social support and self-efficacy on resilience of early career registered nurses. West. J. Nurs. Res. 40, 648-664. doi: 10.1177/0193945916685712

Werner, E. E. (1985). "Stress and protective factors in children's lives," in Longitudinal Studies in Child Psychology and Psychiatry. Vol. 32. New York: John Wiley \& Sons Incorporated, 335-355.

Werner, E. E., and Smith, R. S. (1992). Overcoming the Odds: High Risk Children From Birth to Adulthood. Cornell University Press.

Woldgabreal, Y., Day, A., and Ward, T. (2016). Linking positive psychology to offender supervision outcomes the mediating role of psychological flexibility, general self-efficacy, optimism, and hope. Crim. Justice Behav. 43, 697-721. doi: $10.1177 / 0093854815620816$

Wolin, S. J., and Wolin, S. (2010). The Resilient Self: How Survivors of Troubled Families Rise Above Adversity. 2nd Edn. New York: Villard.

Yu, X., Wang, P., Zhai, X., Dai, H., and Yang, Q. (2015). The effect of work stress on job burnout among teachers: The mediating role of self-efficacy. Soc. Indic. Res. 122, 701-708. doi: 10.1007/s11205-014-0716-5

Yusoff, Y. M., and Chelliah, S. (2010). Adjustment in international students in Malaysian public university. Int. J. Innov. Manag. Technol. 1, 275-278.

Zhao, F. F., Lei, X. L., He, W., Gu, Y. H., and Li, D. W. (2015). The study of perceived stress, coping strategy and self-efficacy of $\mathrm{C}$ hinese undergraduate nursing students in clinical practice. Int. J. Nurs. Pract. 4, 401-409. doi: 10.1111/ijn.12273

Zimmerman, M. A., and Arunkumar, R. (1994). Resiliency research: implications for schools and policy. Soc. Policy Rep. 8, 1-18. doi: 10.1002/j.2379-3988.1994. tb00032.x

Conflict of Interest: The authors declare that the research was conducted in the absence of any commercial or financial relationships that could be construed as a potential conflict of interest.

Copyright (c) 2021 Sabouripour, Roslan, Ghiami and Memon. This is an open-access article distributed under the terms of the Creative Commons Attribution License (CC BY). The use, distribution or reproduction in other forums is permitted, provided the original author(s) and the copyright owner(s) are credited and that the original publication in this journal is cited, in accordance with accepted academic practice. No use, distribution or reproduction is permitted which does not comply with these terms. 